\title{
Sigara İçenlerde Psikolojik Bağımlılığın ve Sigara İçme İsteğinin Bırakma Başarısı Üzerine Etkisinin Değerlendirilmesi
}

\author{
Evaluation of the Effects of Psychological Addiction and \\ Smoking Urge on the Success of Smoking Cessation \\ Ruhuşen Kutlu ${ }^{1}$, Nur Demirbaş ${ }^{1}$, Tuğba Yazıcı ${ }^{1}$, Nazan Karaoğlu ${ }^{1}$
}

${ }^{1}$ Necmettin Erbakan Üniversitesi, Meram Tıp Fakültesi, Aile Hekimliği Anabilim Dalı, Konya, Turkey

Yazışma Adresi: Nur Demirbaş, Necmettin Erbakan Üniversitesi, Meram Tıp Fakültesi, Aile Hekimliği Anabilim Dalı, Konya, Turkey e-posta: ndemirbas76@hotmail.com

Geliş Tarihi/Received: 23 Mart 2021 Kabul Tarihi/Accepted: 20 Haziran 2021

\begin{abstract}
Öz
Amaç: Sigaraya fiziksel bağımlılık kadar psikolojik bağımlılık ve sigara içme arzusu da önemlidir. Bu çalışmanın amacı sigarayı bırakmak isteyen kişilerin bağımlılık düzeyleri ve sigara içme arzularının bırakma başarıları üzerine etkilerinin değerlendirilmesidir.

Hastalar ve Yöntem: Kesitsel tipte analitik bir çalışma olan bu araştırma 10 Ocak 2020-30 Nisan 2020 tarihleri arasında sigara bırakma polikliniğine başvuran kişilerde yapıldı. Katılımcıların sosyodemografik bilgi formu, Fagerström Nikotin Bağımlılık Testi (FNBT) ve Sigaranın Psikolojik Bağımlılığının Değerlendirilmesi Testi (SPBDT) ölçekleri uygulandı ve Karbon monoksit (CO) düzeyleri ölçüldü. Motivasyonel görüşme yapıldı ve gerekli ise tedavileri düzenlendi. Bir ay sonra kontrole çağrılan hastaların tekrar CO düzeyleri ölçülerek Sigara Içme Arzusu Ölçeği (SİAÖ) uygulandı. CO düzeyi 5 ppm ve üzerinde olanlar sigarayı bırakamadı olarak değerlendirildi.

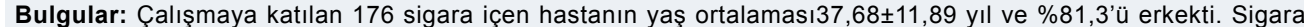
tüketim paket/yıl ortalaması $23,42 \pm 16,06$, FNBT ortalaması $6,13 \pm 2,39$ ve CO $13,33 \pm 6,31$ ppm idi. SPBDT ölçeği puan ortalaması $15,19 \pm 2,63$ (8-24) puan bulundu. FNBT puanına göre hastaların $\% 41,5$ 'i yüksek düzeyde bağımlı, SPBDT puanına göre \%6,8'i $(n=12)$ ciddi bağımlı idi. Bir ay sonra kontrole gelen hastaların kontrol CO düzeyi $5,03 \pm 3,03 \mathrm{ppm}$ olarak bulundu. Buna göre hastaların \%67,6'sı sigarayı bırakamamıştı ve ortalama SiA puanı

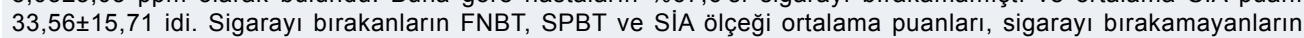
FNBT, SPBT ve SIA puanlarına göre istatistiksel olarak anlamlı olarak daha düşüktü (sırasıyla $p=0,015, p<0,001$ ve $p=0,025)$.

Sonuç: Sigaraya psikolojik bağımlılığı fazla olanların sigara bırakma başarısı düşük olmaktadır. Sigara bırakma polikliniklerine başvuranların nikotin bağımlılığı gibi psikolojik bağımlılıkları da değerlendirilmeli ve motivasyone görüşmeler sırasında sigara içme arzusu ile baş etme yolları anlatılmalıdır.
\end{abstract}

\section{Anahtar Kelimeler: Sigara, psikolojik bağımlılık, sigara içme arzusu}

\section{Abstract}

Aim: Psychological dependence and smoking desire are as important as physical dependence on smoking The aim of this study is to evaluate the effects of the addiction levels and smoking urge of people who want to quit smoking on their success.

Patients and Methods: This study, which is a cross-sectional analytical study, was conducted people who applied to a smoking cessation clinic between 10 January 2020 - 30 April 2020. Sociodemographic information form, the Fagerström Nicotine Dependence Test (FNDT) and the Test for the Assessment of the Psychological Addiction of Smoking (APAS) were applied and CO levels were measured. Motivational interviews were made and treatments were arranged if necessary. The Carbon monoxide (CO) levels of the patients who were called for control one month later were measured and the Questionnaire of Smoking Urges (QSU) was applied. Those with a CO level of $5 \mathrm{ppm}$ and above were considered to be unable to quit smoking.

Results: The average age of 176 patients participating in the study was $37.68 \pm 11.89$ years and $81.3 \%$ were male. The mean of cigarette consumption per pack was $23.42 \pm 16.06$, the average FNDT was $6.13 \pm 2.39$ and the $\mathrm{CO}$ was $13.33 \pm 6.31 \mathrm{ppm}$. APAS scale mean score was $15.19 \pm 2.63$ points. According to the FNDT score, $41.5 \%$ of the patients were highly dependent, and $6.8 \%$ according to the APAS score were severely dependent. Control CO level of the patients who came for control one month later was found to be $5.03 \pm 3.03$ ppm. Accordingly, $67.6 \%$ of the patients could not quit smoking, and the mean QSU score was $33.56 \pm 15.71$. FNDT, APAS and QSU scale mean scores of those who quit smoking were statistically significantly lower than those who did not quit smoking ( $p=0.015, p<0.001$ and $p=0.025$, respectively).

Conclusion: Those who are high psychological dependence to smoking have low success to quitting smoking. Psychological addiction such as nicotine addiction of those who apply to smoking cessation clinics should be evaluated and ways of coping with smoking desire should be explained during motivational interviews.

Key words: Smoking, psychological addiction, smoking urge

Atıf yapmak için: Kutlu R, Demirbaş N, Yazıcı T, Karaoğlu N. Sigara İçenlerde Psikolojik Bağımlılığın ve Sigara İçme İsteğinin Bırakma Başarısı Üzerine Etkisinin Değerlendirilmesi. Selcuk Med J 2021;37(3): 231-237
Açıklama: Yazarların hiçbiri, bu makalede bahsedilen herhangi bir ürün, aygıt veya ilaç ile ilgili maddi çıkar ilişkisine sahip değildir. Araştırma, herhangi bir dış organizasyon tarafından desteklenmedi. Yazarlar çalışmanın birincil verilerine tam erişim izni vermek ve derginin talep ettiği takdirde verileri incelemesine izin vermeyi kabul etmektedirler. 


\section{GíRiş}

Tütün kullanımı kardiyovasküler hastalıklar, akciğer kanseri başta olmak üzere pek çok kansere, ölü doğum, düşük doğum ağırlıklı bebeklerin doğmasına yol açmaktadır. Bu problemlerin önlenmesi mümkün olan en önemli ayağını tütün ve tütün ürünleri oluşturmaktadır (1,2). Dünya Sağlık Örgütü (DSÖ) verileri, 2015 yılında 15 yaş üstü dünya nüfusunun \%20,2'sinin sigara içtiğini, tütünün her yıl dünyada 7 milyon kişinin ölümüne yol açtığını göstermektedir (2). Küresel Yetişkin Tütün Araştırmasının (KYTA) 2016 yılı sonuçlarına göre ülkemizde erişkinler arasında tütün kullanımı $(\% 29,6)$ giderek artmaktadır $(3)$.

Sigara ve tütün içeren diğer ürünlerin içerisindeki nikotin kullanan kişide bağımlılık yaratmaktadır. Nikotin bağımlılığı kronik bir hastalık olarak kabul edilmiş ve nikotinin mental ve davranışsal bozukluklara yol açan psiko-aktif bir madde olduğu belirlenmiştir (4). Nikotin fiziksel bağımlılığını değerlendirmede birçok test bulunmaktadır. En sık Fagerström nikotin bağımlılık testi kullanılır. Bağımlılık düzeyini belirlemek için altı soru içerir. Fagerström Nikotin Bağımlılık Testi'nin (FNBT) yapılan bir çalışma ile sigara bırakma kliniklerinde uygulanabileceği sonucuna varılmıştır (5).

Sigara içmeyi bıraktıktan sonra ilk dönemde görülen belirtiler nikotin yoksunluğu olarak adlandırılır. Anksiyete, irritabilite, konsantrasyon güçlüğü, asabiyet, iştah artışı ve kilo alımı, huzursuzluk, tütün aşermesi en sık nikotin yoksunluk semptomlarındandır (6). Hezer ve arkadaşlarının araştırmasında sigara bırakma deneyimi olan hastaların \%66'sında aşırı sigara içme arzusu, \%58'inde sinirlilik ve \%40'ında depresif duygu durum hali izlenmiştir (7). Sigara bırakmada başarısız olan hastalarda başarılı olanlara göre sigara içme arzusu puan ortalamaları anlamlı düzeyde yüksek saptanmıştır (8). Sigara bırakmada psikolojik bağımlılığın ve sigara içme arzusunun etkisi belirgindir $(9,10)$. Childs ve Wit yaptıkları çalışma ile psikososyal stresin sigara içme arzusunu artırdığına dair kanıtlar buldular (11). Sigara bırakma polikliniklerine başvuran hastaların genellikle nikotine bağlı fiziksel bağımlılıkları değerlendirilmektedir. Sigara bırakmak isteyenlerde psikolojik bağımlılığın ve sigara içme arzusunun belirlenmesi de önemli olabilir. Sigara bırakma başarısına psikolojik bağımlılık düzeyi ne kadar etkilidir? İşte bu nedenle çalışmada sigara bırakmak isteyen hastalarda psikolojik bağımlılığın ve sigara içme arzusunun bırakma başarısı üzerine etkilerinin incelenmesini amaçlandı.

\section{HASTALAR VE YÖNTEM}

Kesitsel tipte analitik bir çalışma olan bu araştırma 10 Ocak 2020- 30 Nisan 2020 tarihleri arasında Meram Tıp Fakültesi Sigara Bırakma Polikliniğine ilk defa başvuran hastalarda yapıldı. Başvuran hastalara çalışmanın amacı anlatılıp sözlü olarak onamları alındı.

\section{Araştırmanın Örneklemi}

Çalışmaya 10 Ocak 2020- 30 Nisan 2020 tarihleri arasında polikliniğe sigara bırakmak için başvuran 358 kişiden çalışmaya katılmaya gönüllü olanlar dahil edildi. Çalışmaya 18 yaşından küçük bireyler, gebeler ve emziren kadınlar dahil edilmedi. Bununla birlikte bırakma tedavisi ardından bir ay sonra kontrole gelmeyen hastalarda çalışma dışı bırakıldı ve çalışma 176 kişinin katılımı ile tamamlandı.

\section{Etik kurul onayı}

Çalışma içinn Necmettin Erbakan Üniversitesi Meram Tıp Fakültesi Etik Kuruldan (2020/2262) onay alındı.

\section{Verilerin toplanması}

Sosyodemografik bilgi formu: Katılımcıların yaş, cinsiyet, eğitim düzeyi ve çalışma durumu ile sigara içme özelliklerinin sorulduğu 10 sorudan oluşan form araştırmacılar tarafından hazırlandı.

Fagerström Nikotin Bağımlılık Testi (FNBT): Heatherton et al. tarafından 1991 yılında geliştirilen ölçeğin, 2004'de Uysal et al. (5) tarafından Türkçe geçerlik çalışması yapılmıştır. FNBT'nin Türkçe versiyonu için FNBT iç tutarlılık kat sayısı 0,584 olarak hesaplandı. Cronbach Alfa katsayısı 0.560 bulunmuştur. Testi orta derecede güvenilir bulunmuş ve sigara bırakma polikliniklerinde nikotin bağımlılığını değerlendirmede ölçüm metodu olarak kullanılabileceği sonucuna varılmıştır. Anket 6 sorudan oluşmaktadır ve alınabilecek puan 0 ile 10 arasında değişmektedir. Çalışmada katılımcıların bağımlılık düzeyleri; $A z$ bağımlılık (0-4), Orta derecede bağımlılık (5-6) ve Yüksek bağımlılık (7-10) olarak kategorize edildi.

Sigaranın Psikolojik Bağımlıı̆̆ının Değerlendirilmesi Testi (SPBDT): İlk hali PoncianoRodríguez ve arkadaşları tarafından sigara bağımlılığını değerlendirmek için, hem klinik araştırmalarda hem de bağımlılık tedaviside yönlendirici 25 sorudan oluşmaktadır. Daha sora 25 soruluk bu testin zor olacağı ve fazla zaman alacağı düşünülerek 8 soruluk kısa versiyonu geliştirilmiştir $(12,13)$. Ölçekteki maddeler "Sıklıkla: 3 puan, Nadiren: 2 puan, Asla: 1puan" olacak şekilde puanlanmaktadır. Ölçek puanı maksimum 24-minimum 8 puan arasında 
olabilir ve bu toplam puan 8-13:Hafif bağımlı; 14-19: Orta bağımlı; 20-24: Ciddi bağımlı olarak kategorize edilir. Ölçeğin iç güvenirlilik kat sayısı $\alpha=0.847$ bulunmuştur.

Sigara İçme Arzusu Ölçeği (Si̇Ö): Sigara bıraktıktan sonraki kontrol başvurusunda en az 20 günlük nikotin yoksunluğu sonrası Sigara İçme Arzusu Ölçeği uygulanır. Cox et al. tarafından 2001 yılında geliştirilen ölçeğin Türkçe geçerlik ve güvenirlik çalışması, Demirezen ve Kurçer tarafından yapılmıştır $(9,14)$. Ölçek yedili Likert yapısında 10 madde olup 1-Hiç katılmıyorum, 2-Katılmıyorum, 3-Kısmen katılmıyorum, 4-Kararsızım, 5-Kısmen katılıyorum, 6-Katılıyorum, 7- Tamamen katılıyorum olarak puanlanmıştır. Ölçekten, alınabilecek puan 10-70 arasında olup, puan yükseldikçe sigara içme arzusunun arttığı şeklinde yorumlanır. Ölçeğin iç güvenilirlik kat sayısı $\alpha=0,92$ bulunmuştur.

Karbonmonoksit (CO) Düzeyi Ölçümü: Ekspiriyum havasında Karbonmonoksit ölçümü kişilerin sigara içip içmediğini belirlemede önemli bir yöntemdir. CO ölçüm cihazları pratik, taşınabilir küçük el cihazlarıdır. CO değerlerini ppm olarak ölçmektedir, aynı zamanda hemoglobine bağlı CO (COhb) oranını da göstermektedir. CO'nun yarılanma ömrü 5 saattir. Her bir sigara içimi $\mathrm{CO}$ düzeyini yaklaşık $8 \mathrm{ppm}$ arttırmaktadır. Saat başı sigara içmek, ekshale edilen nefeste artan CO seviyelerine neden olacaktır (15). Yapılan çalışmalarda CO değeri 5 ppm ve üzerinde ise sigara içiyor olma ihtimalinin çok güçlü olduğu görüşü kabul edilmiştir $(16,17)$.

Çalışmada hastanın nefesinde bulunan $\mathrm{CO}$ düzeyini ölçen piCO+Smokerlyzer (Bedfont Scientific, Harrietsham, England) kullanıldı. Hastadan önce tüm nefesini vermesi, daha sonra derin bir nefes alarak 15 saniye tuttuktan sonra cihazın her hastada değiştirilen ağızlığından hızlıca vermesi istendi. CO düzeyi 4 ppm ve altı olanlar içmiyor, CO düzeyi 5 ppm ve üstü olanlar sigara içiyor olarak değerlendirildi.

\section{Prosedür}

Sözlü olarak onamları alınan katılımcılara 10 soruluk sosyodemografik bilgi formu, Fagerström Nikotin Bağımlılık Testi (FNBT) ve Sigaranın Psikolojik Bağımlılığının Değerlendirilmesi Testi (SPBDT) ölçeklerinden oluşan bir anket formu uygulandı. Katılımcıların karbon monoksit (CO) ölçümü yapıldı. Motivasyonel görüşme sonrasında gerekli görülen hastalara medikal tedavi verildi. Bir ay sonra hastalar kontrole çağrılan katılımcıların kontrolde tekrar CO düzeyi ölçülerek, Sigara İçme Arzusu Ölçeği (Si̇Ä) uygulandı.

\section{Verilerin istatistiksel analizi}

Çalışmada elde edilen bulgular değerlendirilirken, istatistiksel analizler için SPSS (Statistical Package for Social Sciences) for Windows 21,0 programı kullanıldı. Tanımlayıcı istatistiklerin değerlendirilmesinde sayı, yüzde, ortalama ve standart sapma, verilerin normal dağılıma uygunluğuna bakmak için Shapiro Wilk ve Kolmogorov Smirnov testleri kullanıldı. Kategorik verilerin istatistiksel analizi Ki kare testi, nicel verilerin istatistiksel analizi ise normal dağılıma uyduğu için ikili gruplarda bağımsız- $t$ testi, üç ve daha fazla olan gruplarda One Way ANOVA testi (post hoc Tukey test) ile hesaplandı. İstatistiksel olarak $p<0.05$ anlamlı olarak kabul edildi. Parametreler arası korelasyon Pearson korelasyon analizi ile test edildi. Korelasyon katsayısı (r); 0,000-0,249 arası zayıf, 0,250-0,499 arası orta, 0,500-0,749 arası güçlü, 0,750-1,000 arası çok güçlü ilişki olarak değerlendirildi. Her ölçeğin güvenirlik puanları Cronbach alfa ile hesaplandı. FNBT ve SPBT ölçeklerinin sigara bırakmayı tahmin gücünü bulmak için ROC analizi yapılarak eğri altında kalan alan (AUC) hesaplandı. Birinci ayın sonunda $\mathrm{CO}$ değerinin değişimini etkileyen faktörler olabilecek yaş, cinsiyet, paket/yıl ile SPBT ve FNBT puanları kullanılarak logistic regresyon analizi yapıldı, sigara bırakma başarısı üzerine değişkenlerin etkisi değerlendirildi. CO değerinin değişimini etkileyen faktörleri değerlendirmek için ANCOVA testi yapıldı.

\section{BULGULAR}

Çalışmaya dahil edilen 176 hastanın yaş ortalaması $37,68 \pm 11,89(18-67)$ yıldı. Katılımcıların \%81,3'ü $(n=143)$ erkek, \%74,4'ü $(n=131)$ evli, $\% 46,6$ 'sı ( $n=82$ ) ilköğretim mezunu ve \%69,9'u $(n=123)$ çalışıyordu. Hastaların sigara içme paket/yıl ortalaması 23,42 $\pm 16,06$ (1-75) paket/yıl, Fagerstrom nikotin bağımlılık puanı ortalaması $6,13 \pm 2,39(0-10)$

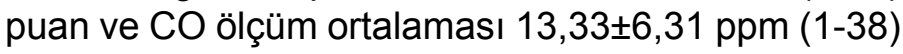
bulundu.

FNBT puanına göre hastaların \%29,0'ı ( $n=51)$ düşük düzeyde bağımlı, \%29,5'i (n=52) orta düzeyde bağımlı ve \%41,5'i ( $n=73)$ yüksek düzeyde bağımlı idi. Başvuran hastaların hepsine motivasyonel görüşme yapıldı. Hastaların \%89,2'sine $(n=157)$ farmakolojik tedavi ve \%8,0'ına $(n=14)$ nikotin replasman tedavisi başlandı (Tablo 1). SPBDT ölçeğinin iç tutarlılık katsayısı 0,684 olarak hesaplandı. Ölçekten alınan ortalama puan $15,19 \pm 2,63$ (8-24) puan olarak bulundu. Buna göre katılımcıların \%27,8'i ( $n=49)$ hafif bağımlı, \%65,3'ü $(n=115)$ orta bağımlı ve $\% 6,8^{\prime} i$ $(n=12)$ ciddi bağımlı idi. 
Table 1. Katılımcıların sigaraya bağımlılık ve sigara bırakma durumlarının karşılaştırılması

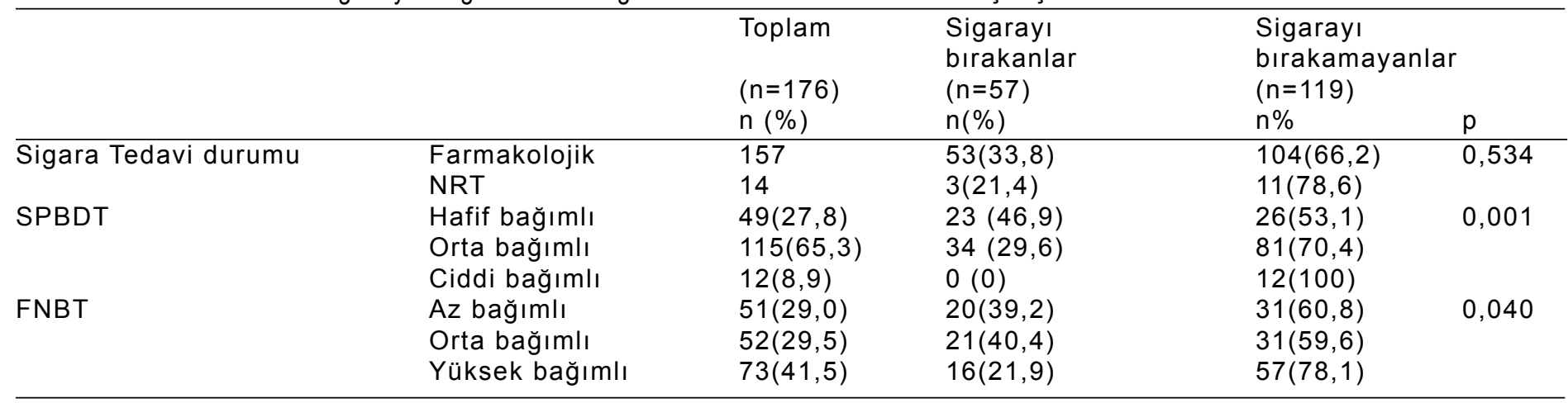

FNBT: Fagerstrom nikotin bağımlııı testi SPBT: Sigaranın Psikolojik Bağımlıığı

Bir ay sonra kontrol için başvuran aynı hastaların yeniden ölçülen CO düzeyi ortalaması 5,03 $\pm 3,03$ ppm olarak bulundu. İlk başvuru ve kontrol CO düzeyi arasında istatistiksel olarak anlamlı ilişki saptandı $(p<0,001)$. Başvuran hemen hemen tüm hastaların $\mathrm{CO}$ düzeyi azalmıştı. Kontrol $\mathrm{CO}$ düzeyi 5 ppm ve üzeri olanlar sigarayı bırakamamış olarak değerlendirildi. Bu duruma göre hastaların \%32,4'ü $(n=57)$ sigarayı bırakmış ve \%67,6'sı $(n=119)$ sigarayı bırakamamıştı. SPBT puanına göre ciddi bağımlı olan katılımcıların hiçbiri birinci ayın sonunda sigarayı bırakamamıştı. SìA ölçeğinin iç tutarlılık kat sayısı 0,845 hesaplandı. Kontrole gelen hastalarda ortalama SiA puanı 33,56 $\pm 15,71$ (10-70) puan olarak bulundu.
Katılımcıların sosyodemografik özellikleri ile FNBT, SPBT ve SIA ölçeği ortalama puanları arasında istatistiksel olarak anlamlı bir ilişki bulunmadı $(p>0,05)$.

Başvurudan bir ay sonra sigarayı bırakanların FNBT $(5,33 \pm 2,10)$, SPBT $(14,18 \pm 1,74)$ ve SiA $(29,91 \pm 13,97)$ ölçeği ortalama puanları, sigarayı bırakamayanların FNBT $(6,18 \pm 2,20)$, SPBT $(15,70 \pm 2,85)$ ve SIA $(35,31 \pm 16,24)$ ortalama puanlarına göre istatistiksel olarak anlamlı düzeyde düşüktü (sırasıyla $p=0,015$, $p<0,001$ ve $p=0,025$ ) (Tablo 2). FNBT ve SPBT puanlarının bir ay sonra sigara bırakma durumunu tahmin gücünü hesaplamak için ROC analizi yapıldığında; FNBT için AUC=0,607 (\%95 Cl 0.521$0.694 ; p=0.022)$ ve SPBT için $A U C=0,676 \quad(\% 95$

Tablo 2. Katılımcıların sosyodemografik özellikleri ile FNBT, SPBT ve Si̇A ölçeklerinin karşılaştırılması

\begin{tabular}{|c|c|c|c|}
\hline & $\begin{array}{l}\text { FNBT } \\
\text { Ort } \pm \text { SD }\end{array}$ & $\begin{array}{l}\text { SPBT } \\
\text { Ort } \pm \text { SD }\end{array}$ & $\begin{array}{l}\text { SiA } \\
\text { Ort } \pm \text { SD }\end{array}$ \\
\hline \multicolumn{4}{|l|}{ Sigara içme durumu } \\
\hline Sigarayı bıraktı & $5,33 \pm 2,10$ & $14,18 \pm 1,74$ & $29,91 \pm 13,97$ \\
\hline Sigarayı bırakamadı & $6,18 \pm 2,20$ & $15,70 \pm 2,85$ & $35,31 \pm 16,24$ \\
\hline$p^{*}$ & 0,015 & $<0,001$ & 0,025 \\
\hline
\end{tabular}

FNBT: Fagerstrom nikotin bağımlılık testi SPBT: Sigaranın Psikolojik Bağımlıı̆ğı SíA: Sigara içme arzusu

* independent t-testi

Tablo 3. FNBT, SPBT ve SİA ölçekleri ile Paket/yıl ve CO düzeylerinin korelasyonu

\begin{tabular}{|c|c|c|c|c|c|c|}
\hline & & FNBT & SPBT & SIA & CO ilk & CO kontrol \\
\hline$\overline{\text { FNBT }}$ & $r$ & 1 & & & & \\
\hline SPBT & $r$ & $0,165^{*}$ & 1 & & & \\
\hline SIA & $r$ & $0,189^{*}$ & $0,223^{*}$ & 1 & & \\
\hline CO ilk & $r$ & $0,223^{* *}$ & 0,101 & 0,075 & 1 & \\
\hline CO kontrol & $r$ & $0,238^{* *}$ & $0,420^{* *}$ & $0,246^{* *}$ & 0,051 & 1 \\
\hline Paket/yıl & $r$ & $0,190^{*}$ & $0,134^{*}$ & $0,226^{* *}$ & $0,498^{* *}$ & 0,460 \\
\hline
\end{tabular}

FNBT: Fagerstrom nikotin bağımlılık testi SPBT: Sigaranın Psikolojik Bağımlılığı SiA: Sigara içme arzusu

${ }^{*} p<0,05{ }^{* *} p<0,001$ 
Tablo 4. Birinci ayın sonunda sigara bırakma durumunu etkileyen değişkenler

\begin{tabular}{lllllll}
\hline & B & S.E. & Wald & df & Sig. & Exp(B) \\
\hline FNBT &, 229 &, 092 & 6,144 & 1 &, 013 & 1,258 \\
SPBT &, 299 &, 082 & 13,319 & 1 &, 000 & 1,348 \\
SiA &, 025 &, 013 & 3,892 & 1 &, 049 & 1,026 \\
Yas &, 038 &, 025 & 2,376 & 1 &, 123 & 1,039 \\
Paket/YII &,- 055 &, 021 & 6,987 & 1 &, 008 &, 946 \\
Cinsiyet &, 306 &, 487 &, 394 & 1 &, 530 & 1,357 \\
Constant & $-6,289$ & 1,813 & 12,036 & 1 &, 001 &, 002
\end{tabular}

FNBT: Fagerstrom nikotin bağımlılık testi SPBT: Sigaranın Psikolojik Bağımlılığı Si̇: Sigara içme arzusu *Logistik regresyon analizi

$\mathrm{Cl}$ 0.598-0.755; p<0.001) bulunmuştur. Buna göre ölçeklerin kesme noktası FBNT için 5 ve SPBT için 14 bulunmuştur.

Katılımcıların FNBT ile SPBT ve SiA puanları arasında pozitif yönde zayıf derecede anlamlı korelasyon vardı $(r=0,165, p=0,029$ ve $r=0,189$, $p=0,012)$. Hastaların ölçülen ilk CO düzeyleri ile FNBT puanı arasında pozitif yönde anlamlı korelasyon varken $\left(r=0,223^{* *}\right)$ bir ay sonraki kontrol $\mathrm{CO}$ düzeyi ile SPBT ve SIA arasında da pozitif yönde anlamlı korelasyon tespit edildi $\left(r=0,420^{* *}, r=0,246^{* *}\right)($ Tablo $3)$.

Birinci ayın sonunda katılımcıların sigara bırakma durumunu etkileyen değişkenleri değerlendirmek için yapılan lojistik regresyon analizi sonuçları Tablo 4'de gösterilmiştir. Birinci ayın sonunda $\mathrm{CO}$ değerinin değişimini etkileyen faktörler yaş, cinsiyet, paket/yıl ile SPBT ve FNBT değerlendirildiğinde; SPBT değeri 1 puan arttığında CO 0.46 ppm ve FNBT değeri 1 puan arttığında $\mathrm{CO} 0,22$ ppm artmakta olduğu bulundu $(p<0,001, p=0,0285)$ (Tablo 5).

\section{TARTIŞMA}

Sigaraya olan bağımlılığın ölçülmesi, etkili bağımlılık tedavisini düzenleyebilmek için gereklidir. Klinisyenler ideal bağımlılık tedavisi için hastanın fiziksel ve psikolojik bağımlılık düzeyleri göz

Tablo 5. Kontrol CO değerini etkileyen faktörler

\begin{tabular}{llll}
\hline & & Estimate & $\mathbf{p}$ \\
\hline Intercept & & -3.2766 & 0.0496 \\
Cinsiyet & Erkek & 0.1377 & 0.8035 \\
& Kadın & 0 & 0.2909 \\
Yaş & & -0.01927 & 0.250 \\
CO İlk değer & & 0.05035 & 0.1541 \\
SPBT & 0.4696 & $<.0001$ \\
FNBT & 0.2214 & 0.0285 \\
Scale & 7.9175 & \\
\hline FNBT: Fagerstrom nikotin bağımlılık & testi SPBT: Sigaranın Psikolojik \\
Bağımlılığı & &
\end{tabular}

önüne alarak, tedaviyi hastanın ihtiyaçlarına göre düzenlemelidir. Sigara bırakma tedavisi başladıktan bir ay sonra hastaların bırakma durumlarının sigara içme arzusu ve sigaraya olan psikolojik bağımlılık düzeyleri ile ilişkisinin değerlendirildiği bu çalışmada; sigaraya psikolojik bağımlılığı fazla olan hastaların sigarayı bırakamadığı ve bu hastalarda sigara içme arzusunun daha yüksek olduğu tespit edildi.

Tütün bağımlılığı, vücutta gerçekleşen farmakolojik olaylar dışında, öğrenilmiş veya şartlanılmış durumlar, bireyin kişilik yapısı ve sosyal ortamların etkisi gibi farklı faktörleri içeren karmaşık bir süreçtir (18). Insanlar genellikle yemek sonrası, bir fincan kahve/ alkollü içecek veya sigara içen arkadaş ortamları gibi belirli durumlarda sigara içerler. Sigara içmek ve bu diğer olaylar arasındaki birçok kez tekrarlanan ilişki, onları çok güçlü bir şekilde birbirine bağlar. Bu durum her sigara içen kişide değişse bile kişi yaşlandıkça hem psikolojik hem de fiziksel nikotine bağımlılığın o kadar yüksek olduğunu düşündürür. Literatürde yapılan çalışmalarda da sigara içme süresi ile fiziksel bağımlılığın arttığı, yetişkinlerde FNBT puanlarının daha yüksek olduğu belirlenmiştir. Daha kısa süre sigara içenlerin sigaraya psikolojik bağımlılık düzeyleri de daha düşük olmaktadır $(12,19)$. Sunulan çalışmada ise katılımcıların yaşı ile nikotin bağımlılık düzeyleri arasında anlamlı ilişki tespit edilmedi. Bunun nedeni sigaraya başlama yaşları ve bağımlılık düzeyleri arasındaki fark olabilir.

Sigaranın nikotine bağlı fiziksel bağımlılığı yanında psikolojik bağımlılığı da olduğunu gösteren çalışmalar literatürde bulunmaktadır. Psikolojik bağımlılık, bireyin stres veya odaklanma intiyacı sırasında sigarayı içmeyi bir çözüm olarak kullanması, belirli durumlarla sigara içmeyi bütünleştirmesidir. Sigara kullanan kişi, sigara ile dikkat ve performansını arttığını, anksiyete ve depresif duygu durumunu azaldığını düşünmektedir $(20,21)$. Sunulan çalışmada katılımcıların yarısından fazlasının sigaraya psikolojik olarak orta düzeyde 
bağımlı olduğu ve sosyodemografik özelliklerin sigaraya psikolojik bağımlılık düzeyini etkilemediği tespit edildi. Bu durum çalışma grubundaki kişilerin orta bağımlılık düzeyinde, bırakma isteği ile başvuran gönüllü verilerinin alınmış olması nedeniyle oluşmuş olabilir.

Sunulan çalışmada sigara tüketimi paket/yılı arttıkça nikotin bağımlılığı, psikolojik bağımlılık ve sigara içme arzusunun arttığı tespit edildi. Paket/yıl sayısı daha düşük olan katıımcıların sigara bırakma başarısı daha yüksekti. Yapılan bir çalışmada günlük içilen sigara sayısı, sigara içme süresi, sigaraya başlama yaşında ile SPBT ve FTND skorlarında anlamlı ilişki bulunmuş ve bu durumun sigara içenleri analiz ederken önemli bir faktör olduğunu gösterilmiştir (12).

Sunulan çalışmada başvurudan bir ay sonra sigarayı bırakanların nikotin bağımlılık ve psikolojik bağımlılık düzeylerinin sigarayı bırakamayanlara göre daha düşük olduğu tespit edildi. Çalışmada katılımcıların nikotin bağımlılık ve psikolojik bağımlılık puanları arasında pozitif yönde anlamlı bir korelasyon olduğu bulundu. Hezer ve Karalezli'de nikotin bağımlılığı ve psikolojik bağımlılık arasında orta düzeyde bir korelasyon tespit ettiklerini belirtmektedir (7). Sigaraya psikolojik bağımlılık arttıkça nikotine olan fiziksel bağımlılığın da arttığı söylenebilir. Yapılan bir çalışmada uyandıktan 5 dakika sonra sigara içenlerdeki depresyon belirtileri sigarayı uyandıktan 1 saat sonra içenlerden 1,6 kat daha fazla bulunmuştur (21). Yine tükrükte stres sonrası kortizol miktarını ölçen bir çalışmada nikotin bağımlılığı düşük bireylerde kortizol seviyesi hızla artarken, nikotin bağımlılığı yüksek olanlarda kortizol seviyesinin yeterince artmadığı bulunmuştur. Bu durum nikotin bağımlılığı ile psikososyal strese bağlı biyolojik tepkiler arasındaki bağlantı olduğunu ortaya koymaktadır(22).

Sigara bırakma tedavisi sırasında başarısızlığı etkileyen en önemli faktörlerden biri sigara içme arzusudur. Nikotinin fiziksel ve psikolojik etkileri sigara içme arzusuna neden olmaktadır. Sigara bırakma tedavisi sırasında içme arzusu ilk günlerde yoğun olarak hissedilmesine rağmen giderek azalır ve ortadan kaybolur $(23,24)$. Allen et al. (25) çalışmalarında sigara içme arzusu yüksek olanların bırakma girişiminde başarısız olduğu saptanmıştır. Araujo et al. (26) da sigara içme arzusunun sigara bırakmayı etkilediğini ve bu konuda daha fazla çalışmanın yapılması gerektiğini vurgulamışlardır. Sunulan çalışmada sigara bırakma tedavisinin birinci ayı sonunda sigarayı bırakamayanların sigara içme arzusunun bırakanlardan daha yüksek olduğu saptandı. Ayrıca sigara tüketim miktarı fazla olan, sigaraya fiziksel ve psikolojik bağımlılığı yüksek olanların sigara içme arzusunun daha fazla olduğu bulundu. Özellikle nikotin yoksunluk semptomlarından aşırı sigara içme isteği ile SiAÖ arasında ise orta düzeyde korelasyon saptanırken yine sigaraya psikolojik bağımlılık ile sigara içme arzusu arasında pozitif yönde bir korelasyon tespit eden çalışmalar vardır $(7,27)$. Sigara bırakma isteği ile başvuran kişilere verilecek davranış terapileri ile sigara içme arzusunun önüne nasıl geçileceğinin anlatılması ve belli bir süre sonra bu isteğin azalarak son bulacağının anlatılması bırakma başarısını arttıracaktır.

Solunum havasında CO düzeyi ölçümü son 24 saattekisigaraiçiminideğerlendirmekiçinkullanılabilen bir yöntemdir (17). Sigara içenler arasında ekshale CO ölçümü ile nikotin bağımlılığını belirlemek isteyen kesitsel bir çalışmada, CO ve FNBT skorları arasında pozitif korelasyon gösterildi (28). Bir başka çalışmada da nefesteki CO düzeylerinin FNBT skorları ile anlamlı şekilde ilişkili olduğu ve FNBT'deki sorulara güvenilir yanıtlar vermeyen hastalar için ekshale CO ölçümleri, yoğun sigara içiminin durumunu tahmin etmek için alternatif bir test olarak kullanılabileceği bildirilmiştir $(16,29)$. Sunulan çalışmada hastaların ölçülen ilk CO düzeyleri ile nikotin ve psikolojik bağımlılık düzeyleri arasında pozitif yönde anlamlı korelasyon varken bir ay sonraki kontrol $\mathrm{CO}$ düzeyi ile sigara içme arzu puanı arasında da pozitif yönde anlamlı korelasyon tespit edildi.

Tek merkezde ve küçük bir örneklem grubunda yapıldığı için bu çalışmanın sonuçları genellenemez. Bununla birlikte çalışmanın sonucunda sigaraya olan psikolojik bağımlılık düzeyinin sigara bırakma girişimlerinde başarı için çok önemli olduğu görülmektedir. Sigara bırakma polikliniklerine başvuran kişilerde fiziksel bağımlılık kadar psikolojik bağımlılık düzeyinin de ölçülmesi ve tedavi planlanırken bu durumun da göz önüne alınmasında faydalı olacaktır. Farmakolojik ve nikotin replasman tedavileri kadar başvuran hastalarda motivasyonel görüşme ve davranış terapilerinde özellikle sigara içme arzusu ile baş etme yollarının ayrıntılı olarak anlatılması başarıyı arttıracağı kanaatindeyiz.

Çıkar Çatışması: Çalışmada herhangi bir çıkar çatışması yoktur.

Finansal Çıkar Çatışması: Çalışmada herhangi bir finansal çıkar çatışması yoktur. 
Yazışma Adresi: Nur Demirbaş, Necmettin Erbakan Üniversitesi, Meram Tıp Fakültesi, Aile Hekimliği AD.Konya, Türkiye

Phone: 05053476672

E-mail: ndemirbas76@hotmail.com

\section{KAYNAKLAR}

1. Kılıç M. Kronik hastalıkların önlenmesinde davranışsal risk faktörlerinin önemi. TAF Prev Med Bull 2011;10(6):733-40.

2. WHO global report on trends in prevalence of tobacco smoking 2000-2025, second edition. Geneva: World Health Organization. Available from: http=//apps. who. int/ iris/ bitstream/ handle/ 10665/272694/9789241514170eng. pdf?ua=1 (Erişim tarihi: 10.12.2019).

3. Küresel yetişkin tütün araştırması 2016. Erişim Adresi: <http:// www.ssuk.org.tr/content.php?haber_id=1485>. Erişim Tarihi: 11.12.2019.

4. Fiore MC, BaileyWC, Dorfman SF, et al. The tobacco use and dependence clinical practice guideline panel, staff, and consortium representatives. A clinical practice guideline for treating tobacco use and dependence: A US Public Health Service Report. JAMA 2000;283(24):3244-54.

5. Uysal MA, Kadakal F, Karşıdağ Ç, et al. Fagerstrom test for nicotine dependence: Reliability in Turkish sample and factor analysis. Tuberk Toraks 2004;52:115-21.

6. Tütün Bağımlılığı İle Mücadele El Kitabı (Hekimler İçin) 2010. Sağlık Bakanlığı Yayın No:796;63. Erişim adresi: https://havanikoru.saglik.gov.tr/dosya/dokumanlar/yayinlar/ tutun-bagimliligi-el-kitabi-hekimler-icin.pdf. Erişim tarihi: 11.12.2019.

7. Hezer H, Karalezli A. Sigaraya psikolojik bağımlılığın sigara içme arzusu ve nikotin yoksunluk semptomlarına etkisi. Ankara Med J 2019;19(4):700-7.

8. Esen AD, Arıca S. Sigarayı bırakmak için başvuranlarda nikotin bağımlılık düzeyi ve sosyodemografik özelliklerin değerlendirilmesi. Ankara Med J 2018;(3):328-36.

9. Demirezen $M$, Kurçer MA. Effect of smoking cessation on anxiety and urge for smoking. $J$ of Dependence 2017;18(2):53-8.

10. Henry SL, Jamner LD, Whalen CK. I (should) need a cigarette: Adolescent social anxiety and cigarette smoking. Ann Behav Med 2012;43(3):383-93.

11. Childs $E$, de Wit $H$. Effects of acute psychosocial stress on cigarette craving and smoking. Nicotine Tob Res 2010;12(4):449-53.

12. Ponciano-Rodríuez G, Valerio-Gutiérrez R, Pliego-Rosas $C A$, et al. Development and evaluation of a new self-rating test to assess the psychological dependence on smoking (TAPDS). J Addict Med Ther 2015;3(1):1016-20.

13. Sağlam L. Nikotin bağımlılığının klinik değerlendirilmesi. Güncel Göğüs Hastalıkları Serisi 2017;40(1):78-89.

14. Cox LS, Tiffany ST, Christen AG. Evaluation of the brief questionnaire of smoking urges (QSU-brief) in laboratory and clinical settings. Nicotine Tob Res 2001;3(1):7-16.

15. Testing for Carbon Monoxide in exhaled breath http://www. healthnz.co.nz/CObreath.htm

16. Deveci SE, Deveci F, Açik Y, et al. The measurement of exhaled carbon monoxide in healthy smokers and nonsmokers. Respir Med 2004;98(6):551-6.

17. Middleton ET, Morice AH. Breath carbon monoxide as an indication of smoking habit. Chest 2000;117:758-63.

18. Uysal, MA. Nikotin sizi nasıl esir alıyor? Tütün bağımlılığının nörobiyolojisi. Güncel Göğüs Hastalıkları Serisi 2016;4(1): 37-43.

19. Esen AD, Seçil Arıca S. Sigarayı bırakmak için başvuranlarda nikotin bağımlılık düzeyi ve sosyodemografik özelliklerin değerlendirilmesi. Ankara Med J 2018;(3):328-36.

20. Fluharty $M$, Taylor AE, Grabski $M$, et al. The association of cigarette smoking with depression and anxiety: A systematic review. Nicotine Tob Res 2017;19:3-13.

21. Bainter T, Selya AS, Oancea SC. A key indicator of nicotine dependence is associated with greater depression symptoms, after accounting for smoking behavior. PLoS One 2020;15(5):e0233656.

22. Morris MC, Mielock AS, Rao U. Salivary stress biomarkers of recent nicotine use and dependence. Am J Drug Alcohol Abuse 2016;42(6):640-8.

23. Fidan F, Pala E, Ünlü M, et al. Sigara bırakmayı etkileyen faktörler ve uygulanan tedavilerin başarı oranları. Kocatepe Tıp Dergisi 2005;3(6):27-34.

24. Niaura R, Shadel W, Britt DM, et al. Response to social stress, urge to smoke, and smoking cessation. Addict Behaviors 2002;27(2):241-50.

25. Allen SS, Bade T, Hatsukami D, et al. Craving, withdrawal, and smoking urges on days immediately prior to smoking relapse. Nicotine Tob Res 2008;10(1): 35-45.

26. Araujo RB, Oliveira MS, Mansur MA. Brazilian validation of the questionnaire of smoking urges. Cad Saúde Pública 2006;22(10):2157-67.

27. Littel M, Franken I, Muris P. Psychometric properties of the brief Questionnaire on smoking urges (QSU-Brief) in a Dutch smoker population. Netherlands J of Psych 2011;1:1-20.

28. Guan NC, Ann AY. Exhaled carbon monoxide levels among Malaysian male smokers with nicotine dependence. Asian Pac J Cancer Prev 2012;13(2):343-6.

29. Babaoğlu E, Karalezli A, Er M, et al. Exhaled carbon monoxide is a marker of heavy nicotine dependence. Turk $\mathrm{J}$ Med Sci 2016;46:1677-81. 